\title{
A Modified Aalborg Inverter Extracting Maximum Power From One PV Array Source
}

\author{
Houqing Wang, Weimin Wu, Shuai Zhang, Yuanbin He, Henry Shu-Hung Chung, and Frede Blaabjerg
}

\begin{abstract}
Distributed Photovoltaic Generation (DPVG) systems have become more important in recent years because of energy pinch and air pollution. Grid-tied inverters, as the indispensable parts of the DPVG systems, have drawn a lot of research attentions. Among various constructors, the Aalborg inverter was proposed as a candidate for the interface between the PV arrays and the power grid for some potential advantages, such as the wide range of input DC voltages, high efficiency, low cost and no leakage current. For a conventional Aalborg inverter, however, in order to gain a symmetrical gird-injected current, when the input DC voltages generated by the PV arrays are not equal, part of the input DC energy has to be discarded, which will reduce the conversion efficiency of the whole system. In this paper, a modified Aalborg inverter with a single input DC source is proposed to extract the maximum DC energy of PV arrays. The operating principle is illustrated via equivalent circuits. The control strategy is designed to balance the capacitor voltages and smooth the gridinjected current. A $110 \mathrm{~V} / 50 \mathrm{~Hz} / 800 \mathrm{~W}$ prototype has been built to verify the validity of the proposed inverter together with the effectiveness of the control strategy.
\end{abstract}

Index Terms-Aalborg inverter, Buck-Boost, maximum power piont tracking (MPPT), photovoltaic system, voltage balance.

\section{INTRODUCTION}

W ITH the development of global economy and the increase of population, environmental pollution and energy shortage are becoming increasingly serious. Distributed Photovoltaic Generation (DPVG), as one of the most important renewable energy resources, has experienced dramatic growth worldwide due to its environmental friendliness [1]-[3]. The grid-tied inverters, connecting the power grid with PV arrays, play an integral role in DPVG systems and have been investigated [4]-[6]. Owning to the advantages of low cost,

Manuscript received January 21, 2019. This work was supported in part by NSFC under Grant 51577114, in part by Shanghai Municipal Education Committee under Grant 14SG43, and in part by the Shanghai Science and Technology Commission under Grant 17040501500 . This paper was presented in part at the 2018 IEEE International Power Electronics and Application Conference and Exposition (PEAC), Shenzhen, China, November 2018.

$\mathrm{H}$. Wang, W. Wu, and S. Zhang are with the Electrical Engineering Department, Shanghai Maritime University, Shanghai, China (e-mail: houqingok@163.com; wmwu@shmtu.edu.cn; zhangshuai.ah@gmail.com).

Y. He is with the Research Institute of Electrical Engineering and Automation, Hangzhou Dianzi University, Hangzhou, China (e-mail: yuanbinhe@hdu.edu.cn).

H. S.-H. Chung is with the Electrical Engineering Department, CityU, Hong Kong, China (e-mail: eeshc@cityu.edu.hk).

F. Blaabjerg is with the Energy Engineering of Aalborg University, Aalborg, Denmark (e-mail: fbl@ et.aau.dk).

Digital Object Identifier 10.24295/CPSSTPEA.2019.00011 high efficiency and small size, transformerless inverters using MOSFET switches are regarded as one of the most promising topologies [7]-[9].

Recently, a grid-tied inverter called Aalborg inverter has been proposed in [5], where it is a new family of high efficiency MOSFET-switch-based half-bridge type inverter with a wide variation of input DC voltage. Similar to the conventional dual mode time-sharing inverters [10], [11], since only one power stage chops at high frequency at any time, the minimum switching power losses and high efficiency of the Aalborg inverter can be realized. Meanwhile, a low drop voltage across the filtering inductors in power loop can further reduce the power losses [12]. So this type of inverter is suitable for the connection between power grids and PV arrays. However, in order to ensure the grid-injected current amplitude value is equal during both positive and negative half line cycles, the maximum energy would not be extracted when the input DC voltages are unbalanced, which will result in sacrificing the whole conversion efficiency of the DPVG systems.

In real PV applications, the output energy of each independent $\mathrm{PV}$ array is influenced by many factors, such as the shape of PV panels, the air humidity [13], the incidence angle [14] and the irradiation temperature [15]. In this scenario, output DC voltages of the two independent PV sources are not always equal. Consequently, input DC energy from the PV modules cannot be fully utilized for the conventional Aalborg inverter if no other measures are taken. Thus, it is significant to make full use of each input source energy and improve the efficiency of Aalborg inverter, when the output DC voltages of independent PV arrays are unequal.

To fully utilize the DC power generated by the PV arrays, a PV string boost stage is generally applied to the interface between the inverters and PV arrays [4], [16]-[18]. The boost circuit could improve the lower input DC voltage and enable both input $\mathrm{DC}$ voltages to be the same for conventional Aalborg inverter, but the auxiliary hardware circuit needs extra devices which leads to a two-stage architecture which inevitably increases the cost and the complexity of the whole system. Based on the operating principle of the coupled inductor, [19] presented a coupled-inductor-based inverter which can regulate the input energy and enable the maximum energy of each PV array to be extracted. The merit of this method is that a magnetic core can be saved and a smaller size and lower cost can be attained [19], [20]. Nevertheless, the leakage inductor of the coupled inductor is required to be very small so that it can be ignored, which will increase the 


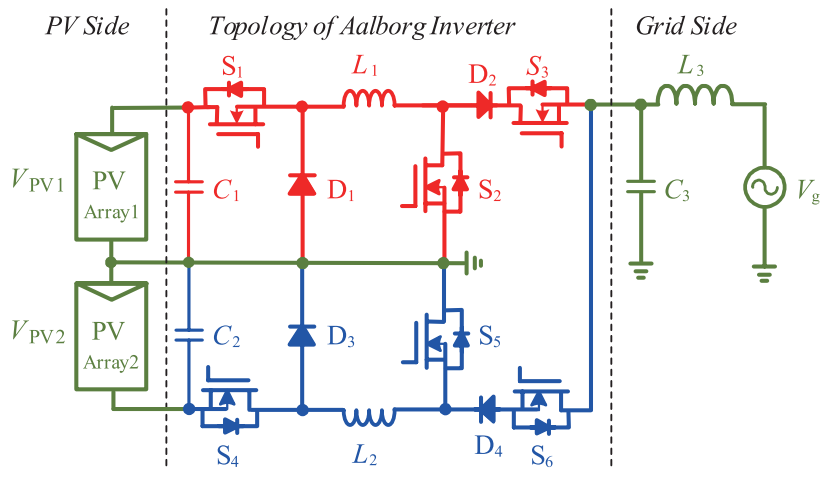

Fig. 1. Conventional Aalborg inverter with two separate input DC sources.

difficulty of the manufacturing process. On the other hand, in terms of software, some methods, like the space vector PWM (SVPWM) [21]-[23], and the predictive control strategy [24], [25], are applied to solve the imbalance issue of DC link capacitor voltage in multilevel multiphase converters, but not applicable to the conventional single-phase Aalborg inverter presented in [5]. This paper presents a modified Aalborg inverter with a single input DC source. Compared with the conventional Aalborg inverter, the main difference in configuration is that the two PV-array sources are replaced with one PV-array source and the mid-line connected ground is dismissed in the proposed inverter. The voltage balance controller is employed in the outer voltage control loop to balance the voltages of electrolytic capacitors.

The rest of this paper is organized as follows. The conventional Aalborg inverter and its principle of operation are first briefly introduced in Section II. Then, the modified Aalborg inverter is presented and analyzed through the equivalent circuits in different working states in Section III. The leakage current of the proposed inverter is analyzed in Section IV. Continuously, in Section V, the whole control strategy is designed to balance the capacitor voltages and get a sinusoidal grid-injected current. The criteria to select the values of passive element are presented in Section VI. Next, an experimental setup is built in Section VII, to verify the validity of the operating principle and the effectiveness of the control strategy. Finally, conclusions are drawn in Section VIII.

\section{Conventional Aalborg InVerter}

Fig. 1 shows the conventional Aalborg inverter with two separate input DC sources. The red devices work during the positive period of grid voltage. The blue devices work during the negative period of grid voltage. As shown in Fig. 2, according to the amplitude relation between the grid voltage $\left(V_{\mathrm{g}}\right)$ and the input DC voltage $\left(V_{\mathrm{PV} 1}, V_{\mathrm{PV} 2}\right)$, the Aalborg inverter can operate in pure "Buck" mode and "Buck-Boost" mode. When the amplitude value of the grid voltage is lower than the DC voltage, it operates in "Buck" state. Otherwise, it operates in "Boost" state. Therefore, it can regulate the output voltage by changing its working states and is suitable for a wide range of input DC voltage. Furthermore, MOSFET devices are adopted, the inductor voltage drop in the power loop is minimized and only one switch is chopping at high

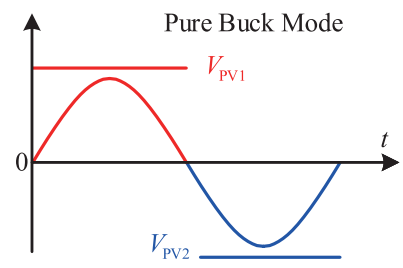

(a)

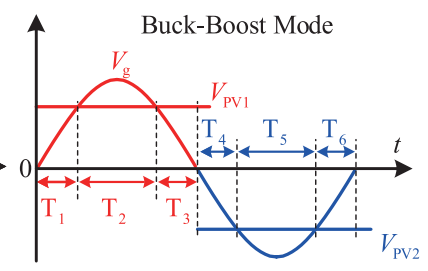

(b)
Fig. 2. Operating modes of the Aalborg inverter: (a) Pure "Buck" mode, $\left|V_{\mathrm{g}}\right|$ is lower than $V_{\mathrm{PV} 1}$ and $V_{\mathrm{PV} 2}$, (b) "Buck-Boost" mode, $\left|V_{\mathrm{g}}\right|$ is higher than $V_{\mathrm{PV} 1}$ and $V_{\mathrm{PV} 2}$.

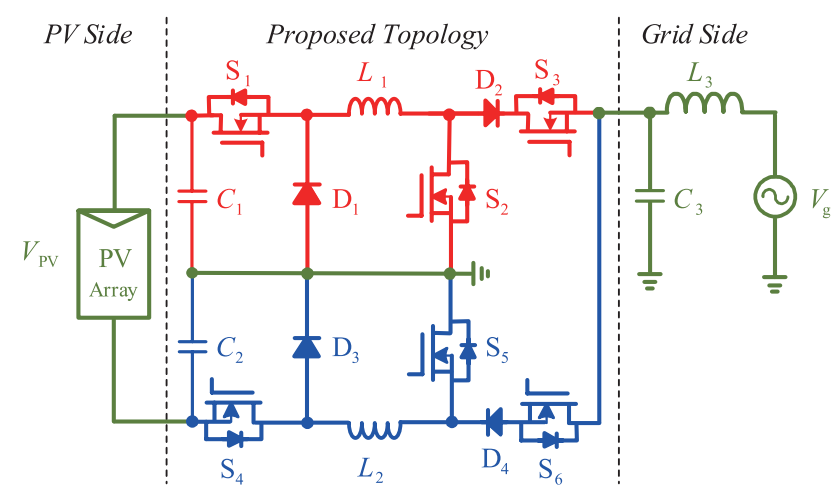

Fig. 3. The modified Aalborg inverter with a single input DC source.

frequency at any time. Thus, high efficiency can be achieved. Besides, no leakage current exists.

However, due to the overshadowed solar panels, installation angle or some other factors in the photovoltaic system [13] [15], it is very hard for two different PV arrays to generate and output equal DC energy. In order to get a symmetrical gridinjected current, differential DC energy of the two PV arrays has to be lost [4]. Therefore, some extra measures should be taken to fully utilize the output energy of the independent PV array sources.

\section{Proposed Single-Input-DC-Source Aalborg INVERTER AND ITS OPERATION}

A single-input-DC-source Aalborg inverter is proposed and shown in Fig. 3. The modified Aalborg inverter inherits the advantages of the conventional Aalborg inverter, such as high efficiency, no leakage current and wide range of input DC voltage. The main difference is that the PV array1 source and array2 source are replaced with one PV array source, and the mid-line connected ground is dismissed. The PV array source first supplies power to the electrolytic capacitors $\left(C_{1}, C_{2}\right)$, then the electrolytic capacitors will supply the energy to the grid side respectively during the positive and negative period of line frequency. The modified Aalborg inverter can fully extract the energy of the PV array.

Similar to the conventional Aalborg inverter, working states of the proposed inverter are also dependent on the amplitude relation between input DC voltage and grid voltage. When $V_{\mathrm{PV}} / 2 \geqslant\left|V_{\mathrm{g}}\right|$, the proposed inverter operates in "Buck" state. While when $V_{\mathrm{PV}} / 2<\left|V_{\mathrm{g}}\right|$, the proposed inverter operates in 


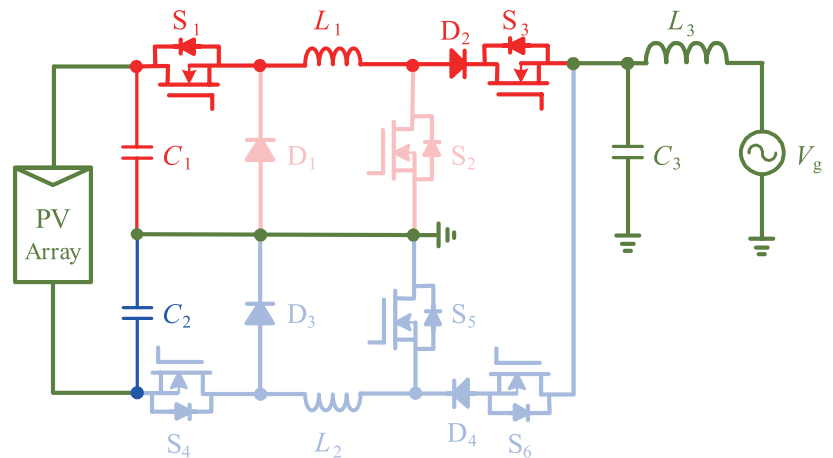

(a)

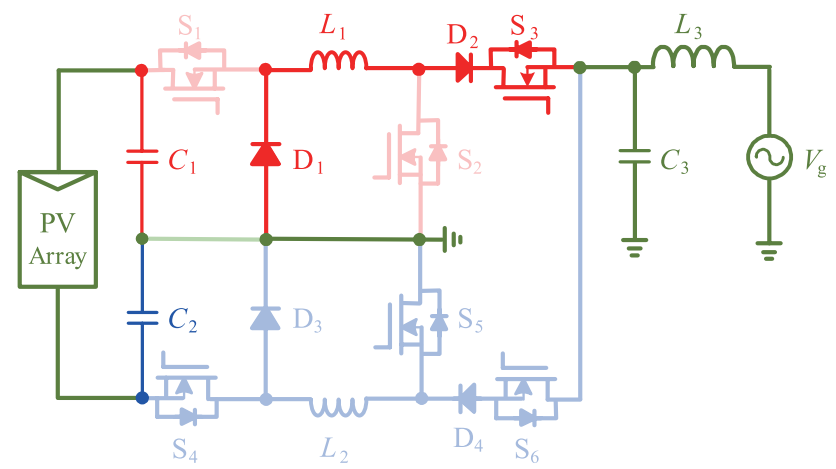

(b)

Fig. 4. Equivalent circuits during "Buck" stage in the positive period of line frequency: (a) Energy storing and (b) energy releasing.

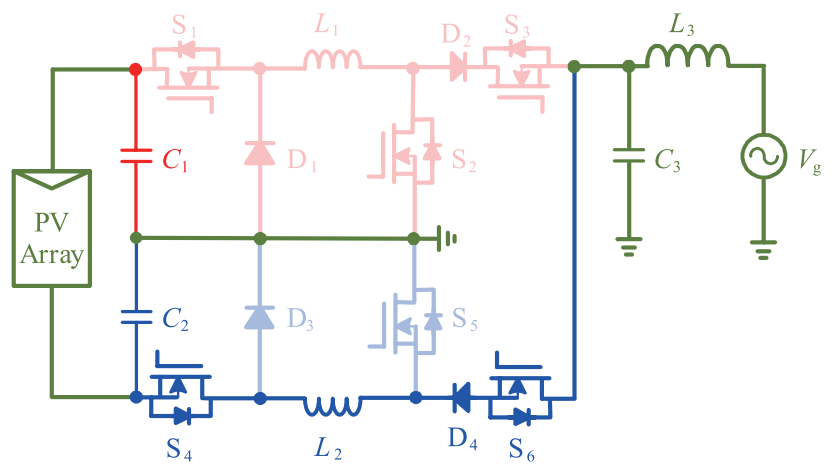

(a)

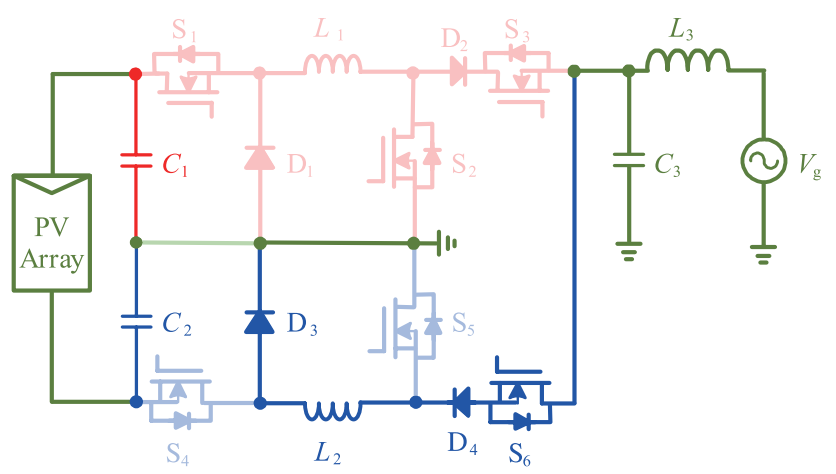

(b)

Fig. 5. Equivalent circuits during "Buck" stage in the negative period of line frequency: (a) Energy storing and (b) energy releasing.

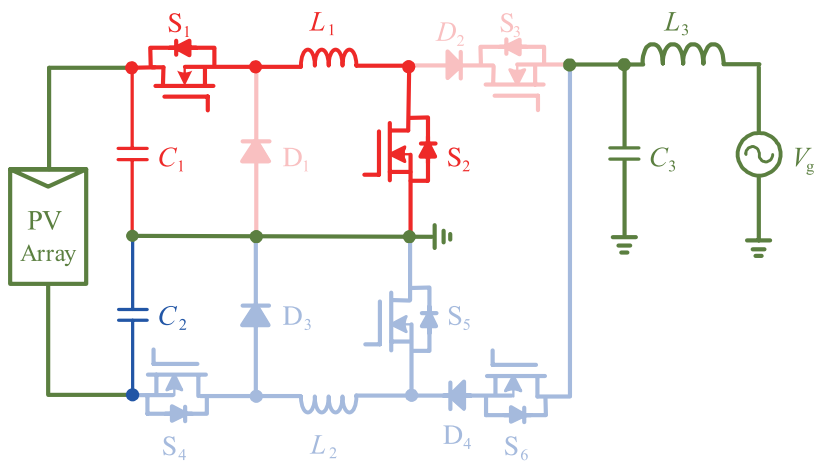

(a)

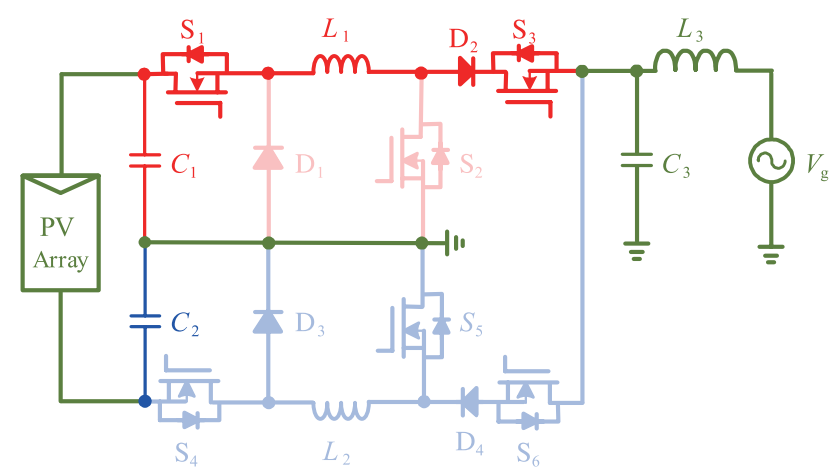

(b)

Fig. 6. Equivalent circuits during "Boost" stage in the positive period of line frequency: (a) Energy storing and (b) energy releasing.

"Boost" state. The operating principle of the proposed singleinput-DC-source Aalborg inverter will be illustrated through the equivalent circuits.

When the proposed inverter works in "Buck" state, the equivalent circuits are shown in Fig. 4 and Fig. 5. During the positive period of line frequency, $\mathrm{S}_{3}$ is on, $\mathrm{S}_{1}$ works in high frequency and the rest of the switches are off. Fig. 4(a) shows that when $\mathrm{S}_{1}$ is on, capacitor $C_{1}$ supplies the energy to $L_{1}$ and the grid. When $S_{1}$ is off, as shown in Fig. 4(b), the energy stored in $L_{1}$ will be released to the grid. During the negative period of line frequency, $\mathrm{S}_{6}$ is on, $\mathrm{S}_{4}$ works in high frequency and the rest of the switches are off. Fig. 5(a) shows that when $S_{4}$ is on, capacitor $C_{2}$ supplies the energy to $L_{2}$ and the grid. When $\mathrm{S}_{4}$ is off, as shown in Fig. 5(b), the energy stored in $L_{2}$ will be released to the grid.

Fig. 6 and Fig. 7 show the equivalent circuits when the proposed inverter works in "Boost" state. During the positive period of line frequency, $\mathrm{S}_{1}$ and $\mathrm{S}_{3}$ are on, $\mathrm{S}_{2}$ works in high frequency and the rest of the switches are off. When $S_{2}$ is on, capacitor $C_{1}$ supplies the energy to $L_{1}$. When $\mathrm{S}_{1}$ is off, capacitor $C_{1}$ and $L_{1}$ provide energy for the grid. During the negative period of line frequency, $\mathrm{S}_{4}$ and $\mathrm{S}_{6}$ are on, $\mathrm{S}_{5}$ works in high frequency and the rest of the switches are off. When $\mathrm{S}_{5}$ is on, capacitor $C_{2}$ supplies the energy to $L_{2}$. When $\mathrm{S}_{5}$ is off, capacitor $C_{2}$ and $L_{2}$ provide energy for the grid.

It should be noted that the PV array supplies the energy to both capacitor $C_{1}$ and capacitor $C_{2}$. 


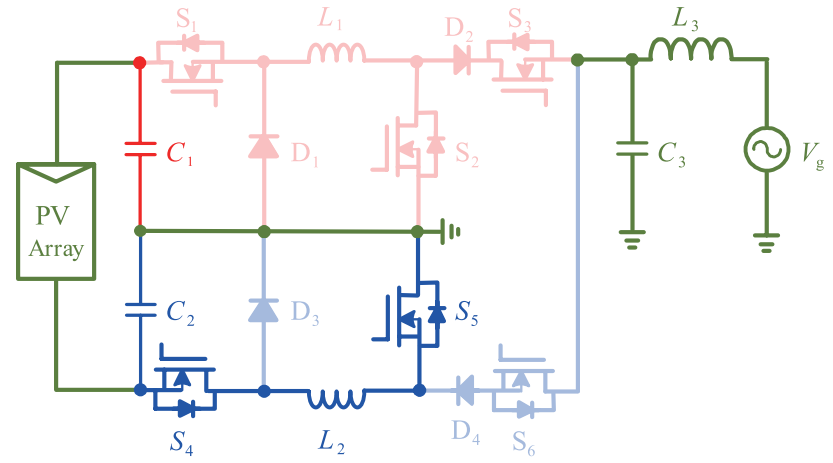

(a)

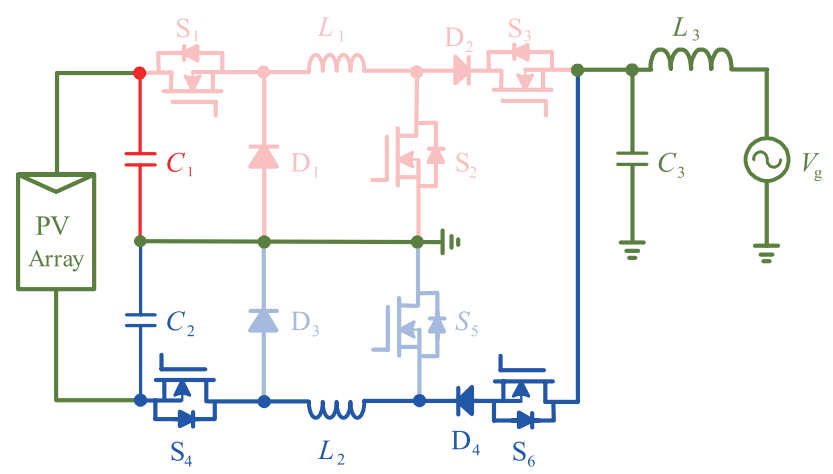

(b)

Fig. 7. Equivalent circuits during "Boost" stage in the negative period of line frequency: (a) Energy storing and (b) energy releasing.

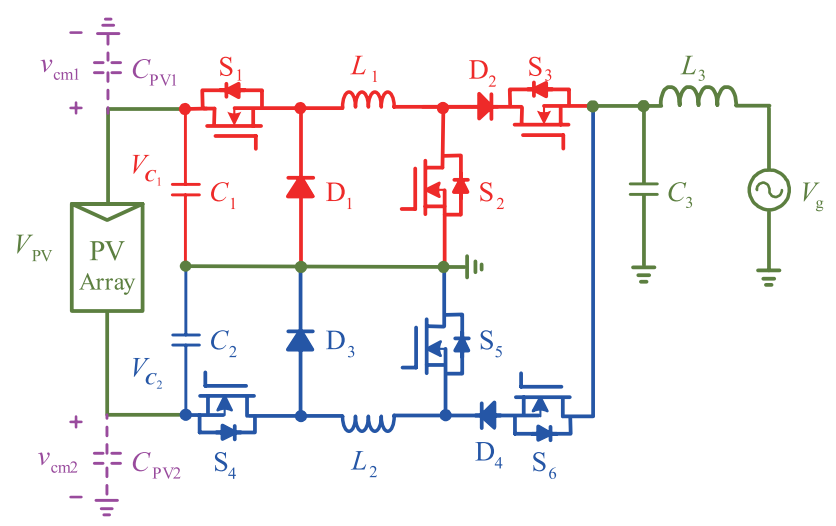

Fig. 8. The structure of the proposed topology with parasitic capacitor.

\section{Leakage Current Analysis of the Modified INVERTER}

As shown in Fig. 1, since one terminal of the PV panel is connected to the earth, there is no leakage current in the conventional Aalborg inverter. Fig. 8 shows the proposed inverter with parasitic capacitor. The leakage current can be derived as

$$
i_{\mathrm{cm}}(t)=C \frac{\mathrm{d} v_{\mathrm{cm}}}{\mathrm{d} t}
$$

Similar to the half bridge topology, the common mode voltage $\left(v_{\mathrm{cm} 1}\right.$ or $\left.v_{\mathrm{cm} 2}\right)$ across the parasitic capacitor is not affected

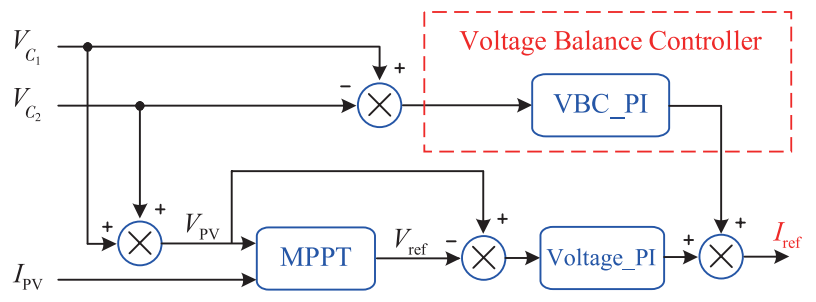

Fig. 9. The outer voltage loop control diagram.

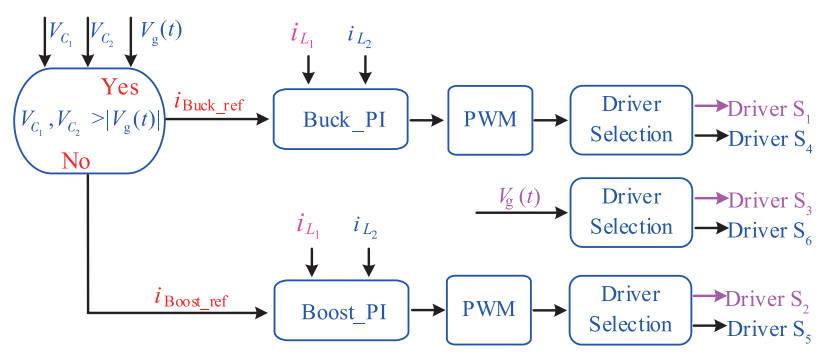

Fig. 10. The internal current loop control diagram.

by switching frequency. If the capacitance of $C_{1}$ and $C_{2}$ are equal and the capacitance value is large enough, the common mode voltage can be derived as

$$
v_{\mathrm{cm} 1}=v_{\mathrm{cm} 2}=V_{C_{1}}=V_{C_{2}}=\frac{1}{2} V_{\mathrm{PV}}
$$

Thus, the leakage current caused by the switch operation is almost equal to zero.

\section{System Control Strategy}

In real applications, some factors, such as the difference of device parameters, the error of sensor and the asymmetric impedance of circuits [19], may cause the electrolytic capacitor voltages to be unbalanced, which distorts the injected current, worsens the circuit performance or even makes the system out of control. In order to balance the electrolytic capacitor voltages, a voltage balance controller (VBC) is employed in this paper. Fig. 9 depicts the outer voltage loop control diagram. The electrolytic capacitor voltages $\left(V_{C_{1}}, V_{C_{2}}\right)$ are measured, and the difference between $V_{C_{1}}$ and $V_{C_{2}}$ will be regarded as the input of the VBC, the output of the VBC and the output of Voltage PI are superimposed as the grid-injected reference current $I_{\text {ref. }}$ VBC is a traditional PI controller. It should be pointed out that the difference of average capacitor voltages is much smaller than the value calculated by PV Maximum Power Point Tracking (MPPT).

Assuming that the electrolytic capacitors $\left(C_{1}\right.$ and $\left.C_{2}\right)$ are large enough so that the voltage disturbance coming from the PV arrays can be ignored, and the $\mathrm{AC}$ source can be regarded as an ideal source. The small signal model of the modified Aalborg inverter is the same as the conventional Aalborg inverter [5].

Fig. 10 describes the internal current loop control diagram of the modified Aalborg inverter, where the input signals include the grid voltage $\left(V_{\mathrm{g}}(t)\right)$, the capacitor voltages $\left(V_{C_{1}}(t), V_{C_{2}}(t)\right)$ and the feedback current of DC inductors $\left(i_{L_{L}}, i_{L_{2}}\right)$. When the capacitor voltage is higher than the amplitude value of grid 
voltage, the modified Aalborg inverter operates in "Buck" state and it is a classical voltage source inverter with $L C L$ filter, which has been analyzed in [26]-[30]. The reference current of "Buck" can be derived as

$$
i_{\text {Buck_ref }}(t)=I_{\text {ref }}(t)
$$

When the modified Aalborg inverter works in "Boost" state, an indirect current control method is adopted since character frequency of the filter is much higher than the control bandwidth [5]. Based on the instantaneous input power equals the instantaneous output power, which can be described as,

$$
V_{C_{X}}(t) \cdot i_{L_{X}}(t)=V_{\mathrm{g}}(t) \cdot i_{\mathrm{g}}(t),(\mathrm{X}=1,2),
$$

the reference current of "Boost" can be derived as,

$$
i_{\text {Boost_ref }}(t)=\frac{V_{\mathrm{g}}(t) \cdot I_{\text {ref }}(t)}{V_{C_{1}}(t)\left(\text { or } V_{C_{2}}(t)\right)}
$$

\section{Parameter Selection of $C_{1}, C_{2}, C_{3}$, And $L_{1}, L_{2}, L_{3}$}

\section{A. The Selection of $C_{1}$ and $C_{2}$}

Similar to the conventional half-bridge type converter, by proper design, the voltage fluctuation could be limited to values which would not affect the MPPT.

The output power $P_{\mathrm{O}}$ can be obtained by the instantaneous voltage and the current of the output power grid.

$$
\begin{aligned}
P_{\mathrm{O}}(t)=v_{\mathrm{g}} \cdot i_{\mathrm{g}} & =V_{\mathrm{gm}} \sin \omega t \cdot I_{\mathrm{gm}} \sin \omega t \\
& =\frac{V_{\mathrm{gm}} \cdot I_{\mathrm{gm}}}{2}-\frac{V_{\mathrm{gm}} \cdot I_{\mathrm{gm}} \cdot \cos 2 \omega t}{2} \\
& =P_{\mathrm{dc}}+\hat{P}_{\mathrm{ac}}(t)
\end{aligned}
$$

where $V_{\mathrm{gm}}$ is the peak value of the grid voltage, $I_{\mathrm{gm}}$ is the peak value of the grid-side current, $\omega=2 \cdot \pi \cdot f, f$ is the grid frequency. It can be seen that the output power $P_{\mathrm{O}}$ consists of DC component $\left(P_{\mathrm{dc}}\right)$ and AC component $\left(\hat{P}_{\mathrm{ac}}(t)\right)$.

Since the input of the inverters is DC power and the output is $\mathrm{AC}$ power, according to the conservation of energy, there is power fluctuation on the DC bus. The instantaneous power difference can be obtained by using (6).

$$
\hat{P}_{\mathrm{ac}}(t)=-\frac{V_{\mathrm{gm}} \cdot I_{\mathrm{gm}} \cdot \cos 2 \omega t}{2}
$$

When $\hat{P}_{\text {ac }}(t)>0$, the capacitor release the energy, which can be derived as

$$
\Delta W=\int \hat{P}_{\mathrm{ac}}(t) \mathrm{d} t=\frac{V_{\mathrm{gm}} \cdot I_{\mathrm{gm}}}{2 \omega}
$$

At the same time, the change of capacitance energy can be obtained according to the change of DC bus voltage.

$$
\begin{aligned}
\Delta W & =\frac{1}{2} C_{X}\left(V_{C_{X}}+\Delta V_{C_{X}}\right)^{2}-\frac{1}{2} C_{X}\left(V_{C_{X}}-\Delta V_{C_{X}}\right)^{2} \\
& =2 C_{X} V_{C_{X}} \cdot \Delta V_{C_{X}},(\mathrm{X}=1,2),
\end{aligned}
$$

where $V_{C_{X}}$ is the average value of $C_{1}$ or $C_{2}, \Delta V_{C_{X}}$ is the voltage ripple of $C_{1}$ or $C_{2}$. The capacitance value of $C_{1}$ or $C_{2}$ can be attained from (8) and (9).

$$
C_{X}=\frac{V_{\mathrm{gm}} \cdot I_{\mathrm{gm}}}{4 \omega \cdot V_{C_{X}} \cdot \Delta V_{C_{X}}}=\frac{P_{\mathrm{dc}}}{2 \omega \cdot V_{C_{X}} \cdot \Delta V_{C_{X}}}=\frac{P_{\mathrm{O}}}{2 \omega \cdot V_{C_{X}} \cdot \Delta V_{C_{X}} \cdot \eta},
$$

where $\eta$ is the efficiency of the whole system. It can be seen that the minimum value of capacitor $C_{X}$ is determined by the maximum value of voltage ripple.

Suppose $P_{\mathrm{O}_{\max }}=800 \mathrm{~W}, \eta=98 \%$, for a maximum ripple of $5 \%$, and substitute other corresponding parameters into (10), the minimum value of $C_{1}$ or $C_{2}$ can be obtained when the inverter works in "Buck-Boost" mode $\left(V_{C_{1}}=V_{C_{2}}=100 \mathrm{~V}\right)$.

$$
C_{1}=C_{2}=2598 \mu \mathrm{F}
$$

Considering some factors, such as power losses, capacitor aging and steady-state characteristics of the system, the DC bus capacitor [31] is finally selected as $C_{1}=C_{2}=4000 \mu \mathrm{F}$.

\section{B. The Selection of $L_{1}, L_{2}, L_{3}$, and $C_{3}$}

In this paper, inductors $L_{1}$ and $L_{2}$ work in continuous conduction mode. The design principle of $L_{1}, L_{2}$ and $C_{3}$ given in [32] is followed. When the inverter operates in pure "Buck" mode, values of $L_{1}$ and $L_{2}$ are obtained from the expression given in [32]

$$
\begin{aligned}
& L_{1}=\frac{V_{C_{1}}(t)-V_{\mathrm{g}}(t)}{2 \Delta i_{L_{1}}} \mathrm{D} \cdot T_{\mathrm{S}}, \\
& L_{2}=\frac{V_{C_{2}}(t)-V_{\mathrm{g}}(t)}{2 \Delta i_{L_{2}}} \mathrm{D} \cdot T_{\mathrm{S}}
\end{aligned}
$$

Typical values of $\Delta i_{L_{X}}(\mathrm{X}=1,2)$ lie in the range of $10 \%$ to $20 \%$ of the full-load [32]. In this paper $P_{\mathrm{O}_{\max }}=800 \mathrm{~W}, V_{\mathrm{g}}=110 \mathrm{~V}$, $T_{\mathrm{S}}=1 / 40 \mathrm{k}$, and suppose the current ripple $\Delta i_{L_{X}}$ is

$$
\Delta i_{L_{X}} \leqslant 15 \% \cdot i_{\mathrm{g}}
$$

By combining (12) and (13), when the inverter works in pure "Buck" mode and D $=0.5$, the minimum DC inductor $\left(L_{1}\right.$ or $\left.L_{2}\right)$ can be calculated as

$$
L_{1}=L_{2} \approx 0.631 \mathrm{mH}
$$

Considering that the inductance value decreases with the increase of current, $L_{1}=L_{2}=0.8 \mathrm{mH}$ is chosen in this paper. In order to achieve wide stability margin and large control band width, a value which is not larger than $L_{1}$ or $L_{2}$ is selected for $L_{3}$ [33].

Likewise, when the proposed inverter works in "Boost" state, 
TABLE I

PARAMETERS FOR EXPERIMENTS

\begin{tabular}{lc}
\hline \hline \multicolumn{1}{c}{ Parameter } & Value \\
\hline DC inductor $L_{1}, L_{2}$ & $0.8 \mathrm{mH}$ \\
Electrolytic capacitor $C_{1}, C_{2}$ & $4000 \mu \mathrm{F}$ \\
Filter inductor $L_{3}$ & $0.8 \mathrm{mH}$ \\
Filter capacitor $C_{3}$ & $2 \mu \mathrm{F}$ \\
Grid voltage $V_{\mathrm{g}}$ & $110 \mathrm{~V}$ \\
Grid frequency $f_{\mathrm{o}}$ & $50 \mathrm{~Hz}$ \\
Switching frequency $f_{\mathrm{sw}}$ & $40 \mathrm{kHz}$ \\
Input DC voltage $V_{\mathrm{PV}}$ & $200 \mathrm{~V} / 400 \mathrm{~V}$ \\
\hline
\end{tabular}

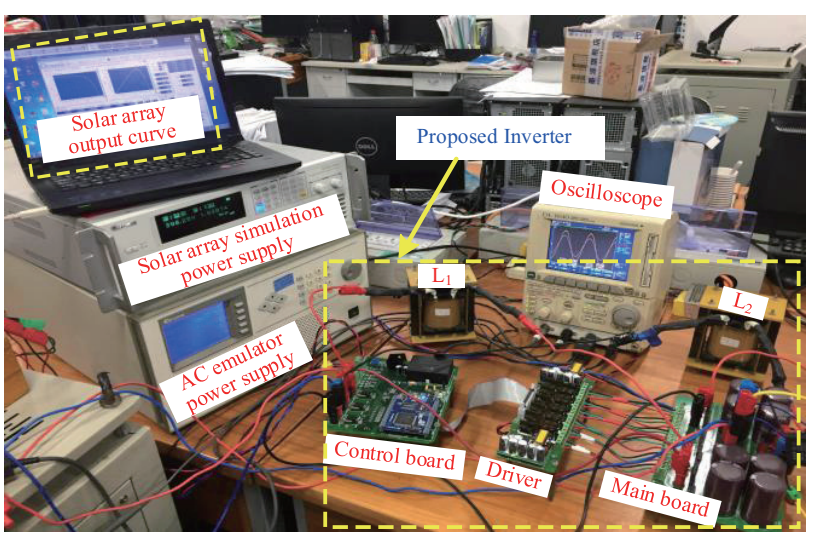

Fig. 11. Experimental prototype developed for the proposed inverter.

the value of $C_{3}$ can also be obtained from the expression derived in [32]

$$
C_{3}=\frac{V_{\mathrm{g}}(t)}{2 R_{\mathrm{f}} \Delta v} \mathrm{D} \cdot T_{\mathrm{S}},
$$

wherein, $R_{f}$ is the equivalent resistor for calculating the generated power. Suppose the voltage ripple $\Delta v$ is

$$
\Delta v \leqslant 15 \% \cdot v_{\mathrm{g}}
$$

Based on (15) and (16), when the inverter works in pure "Boost" mode and $\mathrm{D}=0.3548$, the minimum capacitor $\left(C_{3}\right)$ can be calculated as

$$
C_{3} \approx 1.955 \mu \mathrm{F},
$$

$C_{3}=2 \mu \mathrm{F}$ is chosen in this paper.

\section{EXPERIMENTS}

As shown in Fig. 11, a $110 \mathrm{~V} / 50 \mathrm{~Hz} / 800 \mathrm{~W}$ prototype has been constructed to verify previous analysis. The parameters of the system are listed in Table I. A DSP controller (TMS320LF28335) is adopted to complete all the control tasks. A solar array power supply (Chrome $62150 \mathrm{H}-600 \mathrm{~s}$ ) is provided

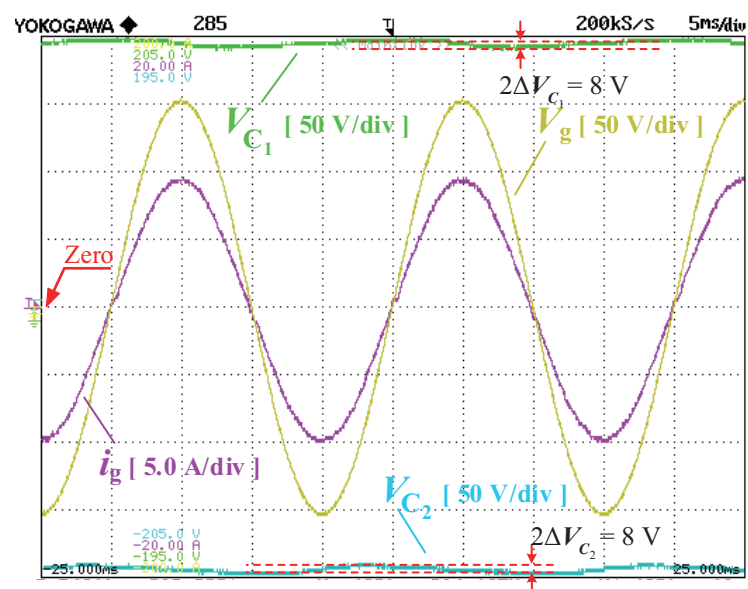

(a)

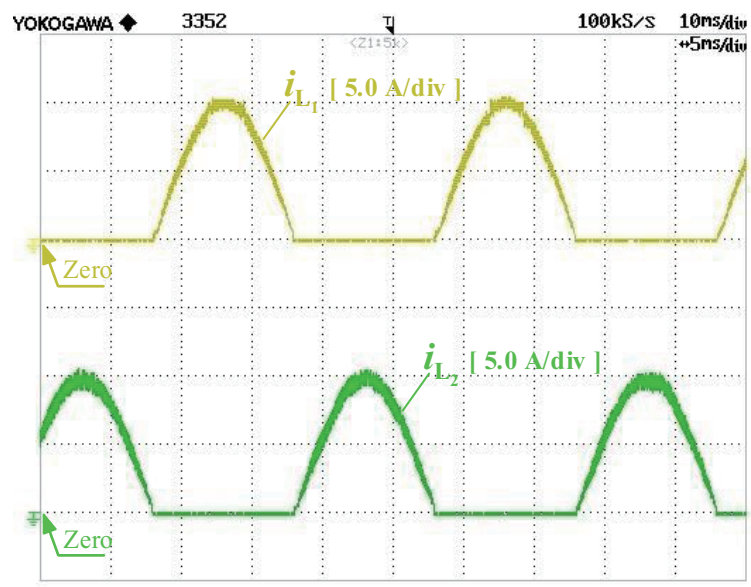

(b)

Fig. 12. Experimental waveforms in pure "Buck" mode, when $V_{\mathrm{PV}}=400 \mathrm{~V}$, $V_{\mathrm{g}}=110 \mathrm{~V}$ and $P_{\mathrm{O}}=770 \mathrm{~W}$. (a) Measured capacitor voltages $\left(V_{C_{C}}, V_{C_{2}}\right)$, gridinjected current $\left(i_{\mathrm{g}}(t)\right)$, grid voltage $\left(V_{\mathrm{g}}(t)\right)$. (b) Measured DC inductor currents $\left(i_{L_{1}}, i_{L_{2}}\right)$.

to imitate the PV array, and the grid voltage is emulated by using a programmable AC Source of Chroma 6530. The experimental results are displayed in Figs. 11-14, respectively.

Figs. 12-14 show the experimental results when $V_{\mathrm{PV}}=400 \mathrm{~V}$, $V_{\mathrm{g}}=110 \mathrm{~V}$, the proposed inverter operates in pure "Buck" mode. Fig. 12 depicts the measured electrolytic capacitor voltages of $V_{C_{1}}(t)$ and $V_{C_{2}}(t)$, the grid voltage of $V_{\mathrm{g}}(t)$ and the grid-injected current of $i_{\mathrm{g}}(t)$. From Fig. 12, it can be seen that the grid-injected current is in a good sinusoidal shape and the electrolytic capacitor voltages are almost balanced through the control of VBC $\left(V_{C_{1}}=198.68 \mathrm{~V}, V_{C_{2}}=200.45 \mathrm{~V}\right)$. Moreover, the electrolytic capacitor ripple voltage is very small and the ripple voltage is about $4 \mathrm{~V}$. The power factor $(\mathrm{PF})$ and the THDs of the grid-injected current and voltage are measured in Fig. 13. The $\mathrm{PF}$ is almost one unit (0.9974) and the THD of the grid-injected current is only $1.86 \%$. Fig. 14 shows that the proposed inverter has a very high MPPT's efficiency, which is around $99.20 \%$.

When $V_{\mathrm{PV}}=200 \mathrm{~V}, V_{\mathrm{g}}=110 \mathrm{~V}$, the proposed inverter operates in "Buck-Boost" mode and the experimental results are shown in Figs. 15-17. Fig. 15 shows the capacitor voltages of $V_{C_{1}}(t)$ and $V_{C_{2}}(t)$, the grid voltage of $V_{\mathrm{g}}(t)$ and the injected current of 


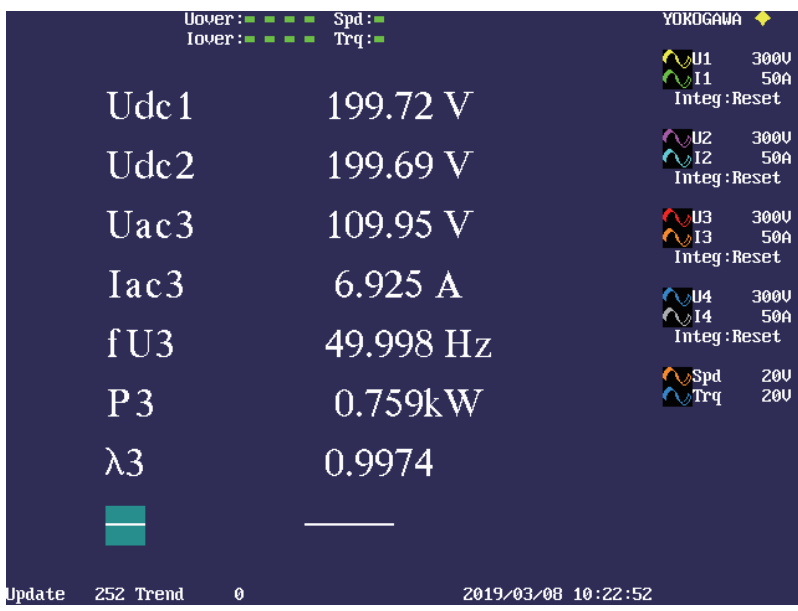

(a)

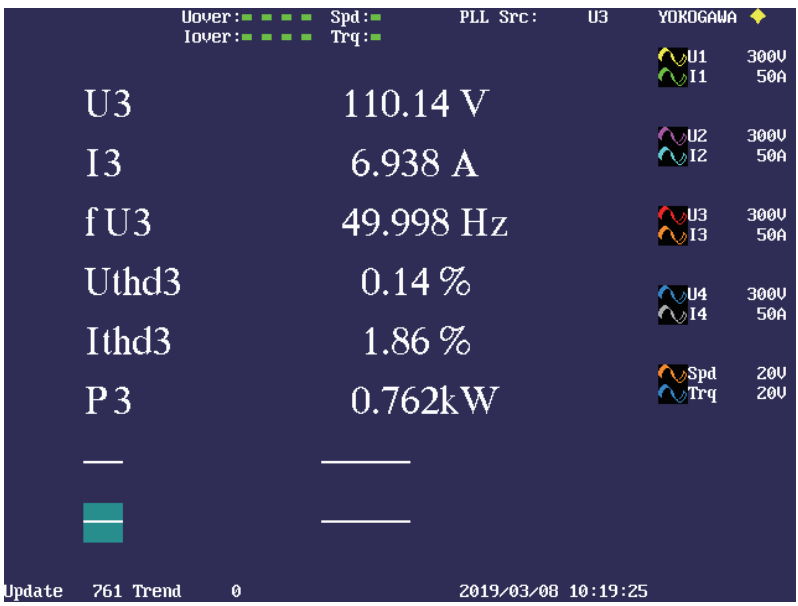

(b)

Fig. 13. The measured results in pure "Buck" mode, when $V_{\mathrm{PV}}=400 \mathrm{~V}, V_{\mathrm{g}}=110 \mathrm{~V}$ and $P_{\mathrm{O}}=760 \mathrm{~W}$. (a) The power factor of the system. (b) The THD values of output voltage and current.

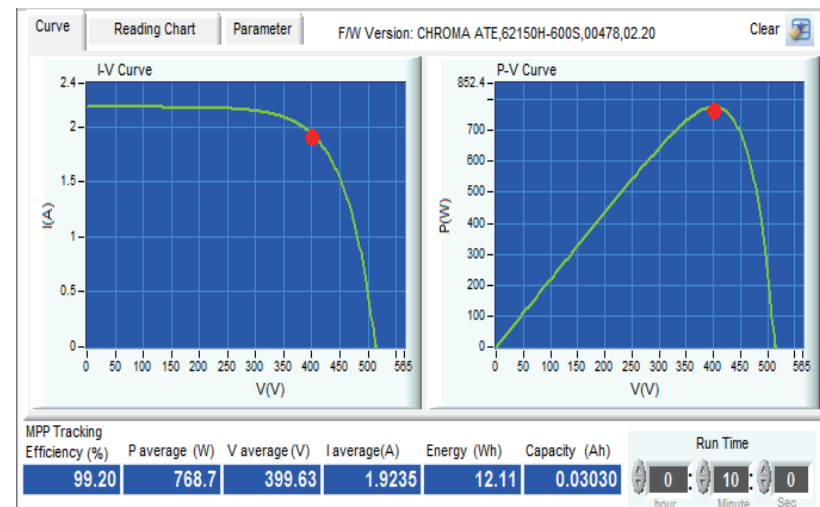

Fig. 14. MPPT results in pure "Buck" mode, when $V_{\mathrm{PV}}=400 \mathrm{~V}, V_{\mathrm{g}}=110 \mathrm{~V}$ and $P_{\mathrm{O}}=770 \mathrm{~W}$.

$i_{\mathrm{g}}(t)$. It can be seen that grid-injected current also has a pretty sinusoidal waveform except for a little distortion resulted from the Buck-Boost switching point. The electrolytic capacitor voltages are kept balanced $\left(V_{C_{1}}=101.3 \mathrm{~V}, V_{C_{2}}=101.2 \mathrm{~V}\right)$ and the average voltage of each capacitor is equal to half of the PV array output

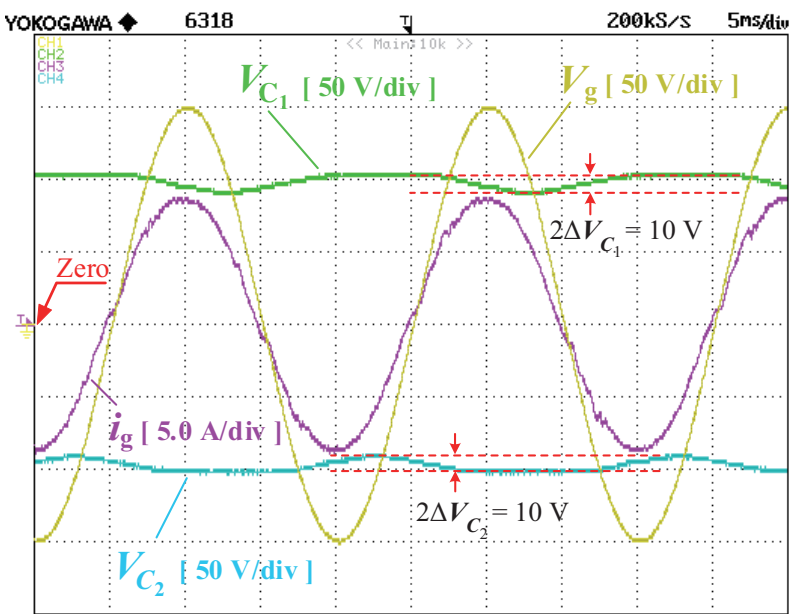

(a)

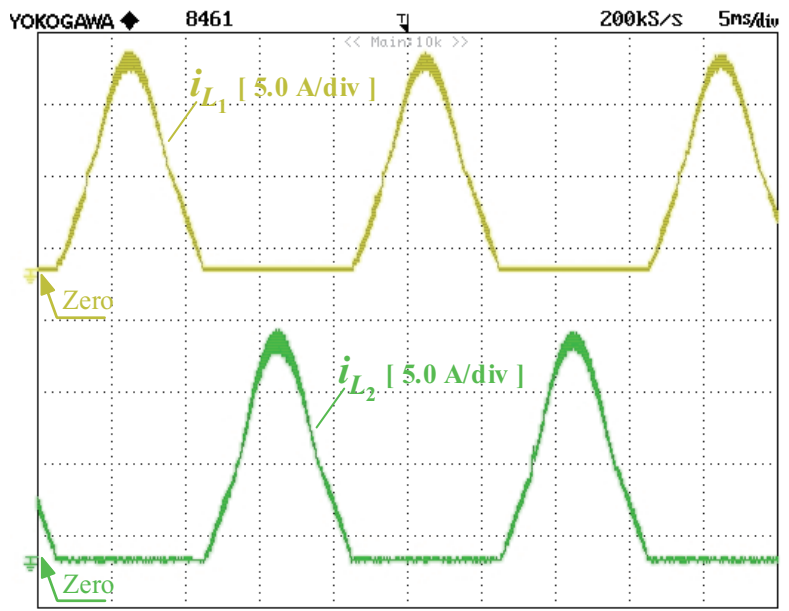

(b)

Fig. 15. Experimental waveforms in "Buck-Boost" mode, when $V_{\mathrm{PV}}=200 \mathrm{~V}$, $V_{\mathrm{g}}=110 \mathrm{~V}$ and $P_{\mathrm{O}}=770 \mathrm{~W}$. (a) Measured capacitor voltages $\left(V_{C_{1}}, V_{C_{2}}\right)$, gridinjected current $\left(i_{\mathrm{g}}(t)\right)$, grid voltage $\left(V_{\mathrm{g}}(t)\right)$. (b) Measured DC inductor currents $\left(i_{L_{1}}, i_{L_{2}}\right)$.

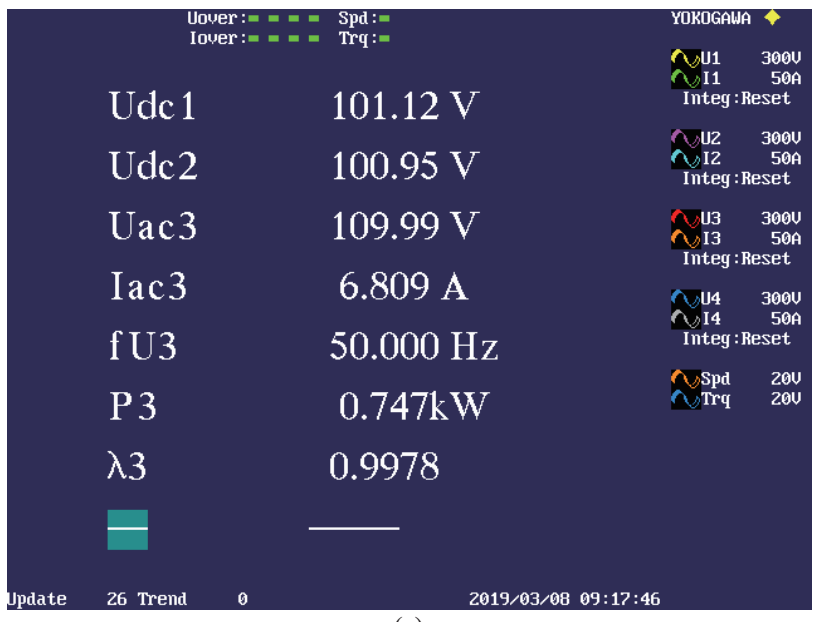

(a)

Fig. 16. Measured results in "Buck-Boost" mode, when $V_{\mathrm{PV}}=200 \mathrm{~V}, V_{\mathrm{g}}=110 \mathrm{~V}$ and $P_{\mathrm{O}}=750 \mathrm{~W}$. (a) The power factor of the system. 


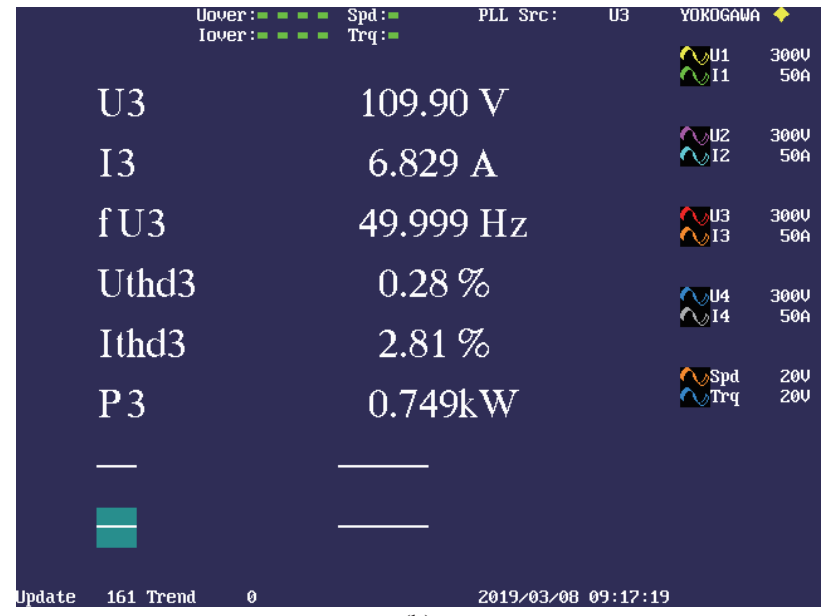

(b)

Fig. 16. (Continued..) The measured results in "Buck-Boost" mode, when $V_{\mathrm{PV}}=200 \mathrm{~V}, V_{\mathrm{g}}=110 \mathrm{~V}$ and $P_{\mathrm{O}}=750 \mathrm{~W}$. (b) The THD values of output voltage and current.

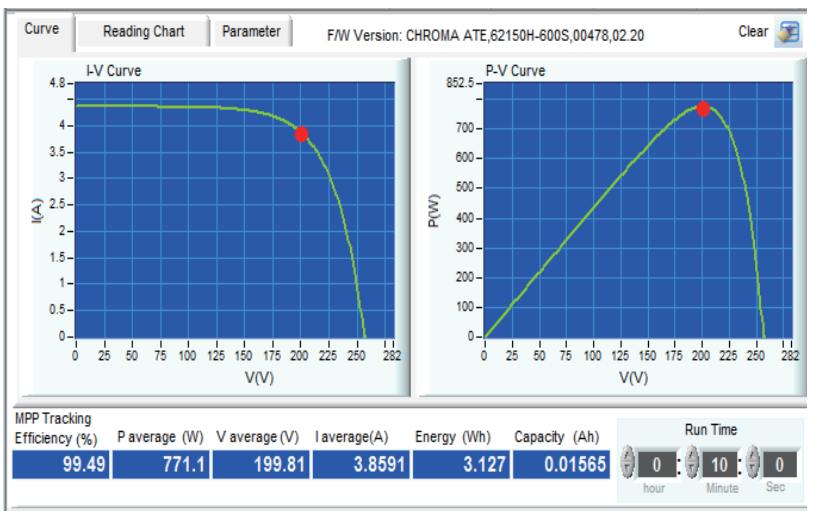

Fig. 17. MPPT results in "Buck-Boost" mode, when $V_{\mathrm{PV}}=200 \mathrm{~V}, V_{\mathrm{g}}=110 \mathrm{~V}$ and $P_{\mathrm{O}}=770 \mathrm{~W}$.

voltage, which means the proposed control method can realize the capacitor voltage balance of the modified Aalborg inverter. At the same time, compared with the electrolytic capacitor voltages, value of the voltage ripple is about $5 \mathrm{~V}$, which is consistent with previous analysis. Fig. 16 shows that the PF is equal to 0.9978 and the THD of the output current and voltage are slightly larger than that in pure "Buck" mode, because of the Buck-Boost switching point. MPPT's results are shown in Fig. 17, it can be seen that the MPPT's efficiency, about $99.49 \%$, is also very high.

\section{CONCLUSION}

This paper presents a modified Aalborg inverter with a single input DC source to maximize power yield from the PV array. The characteristics of this inverter can be summarized as follows.

1) Similar to the conventional Aalborg inverter proposed in [5], the inductor voltage drop in power loop is minimized, MOSFET switches are adopted and only one switch operates at high frequency at any time, which ensures that the proposed inverter has a high efficiency. Besides, the input DC voltage can vary widely and no leakage current exists.
2) Different from the conventional Aalborg inverter proposed in [5], the modified Aalborg inverter only requires one PV array source, rather than two. The mid-line connected ground is dismissed. The PV array source first supplies power to the electrolytic capacitors $\left(C_{1}, C_{2}\right)$, then the electrolytic capacitors will supply the energy to the grid side respectively during positive and negative period of line frequency. The modified Aalborg inverter can fully extracted the energy of the PV array.

The operating principle of the proposed inverter has been illustrated through the equivalent circuits. The whole control strategy is designed to balance the capacitor voltages and obtain a sinusoidal grid-injected current. Experimental results based on an $110 \mathrm{~V} / 50 \mathrm{~Hz} / 800 \mathrm{~W}$ prototype have verified the feasibility of theoretical analysis and the effectiveness of the control strategy.

\section{REFERENCES}

[1] S. Jiang, C. Wan, C. Chen, E. Cao, and Y. Song, "Distributed photovoltaicgeneration in the electricity market: Status, mode and strategy," CSEE Journal of Power and Energy Systems, vol. 4, no. 3, pp. 263-272, Sept. 2018.

[2] D. Cheng, B. A. Mather, R. Seguin, J. Hambrick, and R. P. Broadwater,"Photovoltaic (PV) impact assessment for very high penetration levels, "IEEE Journal of Photovoltaics, vol. 6, no. 1, pp. 295-300, Jan. 2016.

[3] N. Haghdadi, A. Bruce, I. MacGill, and R. Passey, "Impact of distributedphotovoltaic systems on zone substation peak demand," IEEE Transactions on Sustainable Energy, vol. 9, no. 2, pp. 621629, Apr. 2018

[4] E. Serban, F. Paz, and M. Ordonez, "Improved PV inverter operatingrange using a miniboost," IEEE Transactions on Power Electronics, vol. 32, no. 11,pp. 8470-8485, Nov. 2017.

[5] W. Wu, J. Ji, and F. Blaabjerg, "Aalborg inverter - A new type of "buckin buck, boost in boost" grid-tied inverter," IEEE Transactions on Power Electronics, vol. 30, no. 9, pp. 4784-4793, Sept. 2015.

[6] A. Chakravartula and B. G. Fernandes, "Neutral point clamped MOSFETinverter with full-bridge configuration for non-isolated grid-tiedphotovoltaic system," IEEE Journal of Emerging and Selected Topics in Power Electronics, vol. 5,no. 1, pp. 445-457, Mar. 2017.

[7] S. Zhang, W. Wu, H. Wang, Y. He, H. S. Chung, and F. Blaabjerg,"Voltage balance control based Aalborg inverter with single source inphotovoltaic system," in 2018 IEEE International Power Electronics and Application Conference and Exposition (PEAC), Shenzhen, China, 2018, pp. 1-4.

[8] M. Islam and S. Mekhilef, "Efficienttransformerless MOSFET inverterfor a grid-tied photovoltaic system," IEEE Transactions on Power Electronics, vol.31, no. 9, pp. 6305-6316, Sept. 2016.

[9] J. F. Ardashir, M. Sabahi, S. H. Hosseini, F. Blaabjerg, E. Babaei, and G. B.Gharehpetian, "A single-phase transformerless inverter with charge pumpcircuit concept for grid-tied PV applications," IEEE Transactions on Industrial Electronics,vol. 64, no. 7, pp. 5403-5415, July 2017.

[10] W. Wu and T. Tang, "Dual-mode time-sharing cascaded sinusoidalinverter," IEEE Transactions on Energy Conversion, vol. 22, no. 3, pp. 795-797, Sept.2007.

[11] N. A. Ahmed, H. W. Lee, and M. Nakaoka, "Dual-mode timesharingsinewave-modulation soft switching boost full-bridge onestage powerconditioner without electrolytic capacitor DC link," IEEE Transactions on Industry Applications, vol. 43, no. 3, pp. 805-813, May-June 2007.

[12] W. Wu, Z. Wang, J. Ji, and F. Blaabjerg, "Performance analysis of newtype grid-tied inverter-Aalborg Inverter," in 2014 16th European Conference on Power Electronics and Applications, Lappeenranta, 2014, pp. 1-10.

[13] B. Burduhos, I. Vişa, A. Duță, and M. Neagoe, "Analysis of theconversion efficiency of fi ve types of photovoltaic modules during highrelative humidity time periods," IEEE Journal of Photovoltaics, vol. 8, no. 6, pp.1716-1724, Nov. 2018.

[14] R. J. Beal, B. G. Potter, and J. H. Simmons, "Angle of incidence effectson external quantum efficiency in multicrystalline silicon 
photovoltaics," IEEE Journal of Photovoltaics, vol. 4, no. 6, pp. 1459-1464, Nov. 2014.

[15] T. J. Silverman, M. G. Deceglie, I. Subedi, N. J. Podraza, I. M.Slauch, V. E. Ferry, and I. Repins, "Reducing operating temperature inphotovoltaic modules," IEEE Journal of Photovoltaics, vol. 8, no. 2, pp. 532-540,Mar. 2018

[16] G. R. Chandra Mouli, J. H. Schijffelen, P. Bauer, and M. Zeman,"Design and comparison of a 10-kW interleaved boost converter for PVapplication using Si and SiC devices," IEEE Journal of Emerging and Selected Topics in Power Electronics, vol. 5, no. 2, pp. 610-623, Jun. 2017.

[17] F. Reverter and M. Gasulla, "Optimal inductor current in boost DC/ DCconverters regulating the input voltage applied to low-power photovoltaicmodules," IEEE Transactions on Power Electronics, vol. 32, no. 8, pp. 6188-6196,Aug. 2017.

[18] R. Errouissi, A. Al-Durra, S. M. Muyeen, and A. El Aroudi, "Robustfeedback-linearisation control of a boost converter feeding a grid-tiedinverter for PV applications," IET Power Electronics, vol. 11, no. 3, pp.557-565, Mar. 2018.

[19] H. Wang, W. Wu, H. S. Chung, and F. Blaabjerg, "CoupledinductorbasedAalborg inverter with input DC energy regulation," IEEE Transactions on Industry Applications, vol. 65, no. 5, pp. 3826-3836, May 2018.

[20] H. Wang, W. Wu, Y. Li, and F. Blaabjerg, "A coupled-inductorbasedbuck-boost AC-DC converter with balanced DC output voltages," IEEE Transactions on Power Electronics, vol. 34, no. 1, pp. 151-159, Jan. 2019.

[21] A. Dekka, B. Wu, N. R. Zargari, and R. L. Fuentes, "A spacevectorPWM-based voltage-balancing approach with reduced current sensors formodular multilevel converter," IEEE Transactions on Industry Applications, vol. 63, no. 5,pp. 2734-2745, May 2016.

[22] W. Liu, H. Jin, W. Yao, and Z. Lu, "An interleaved PWM method withbetter voltage-balancing ability for half-bridge three-level DC/ DCconverter," IEEE Transactions on Power Electronics, vol. 33, no. 6, pp. 4594-4598,Jun. 2018

[23] L. Gang, W. Dafang, W. Miaoran, Z. Cheng, and W. Mingyu, "Neutralpointvoltage balancing in three-level inverters using an optimized virtualspace vector PWM with reduced commutations," IEEE Transactions on Industry Applications, vol. 65, no. 9, pp. 6959-6969, Sept. 2018

[24] A. Mora, M. Urrutia, R. Cárdenas, A. Angulo, M. Espinoza, M. Díaz, andP. Lezana, "Model-predictive-control-based capacitor voltage balancingstrategies for modular multilevel converters," IEEE Transactions on Industry Applications, vol. 66, no. 3, pp. 2432-2443, Mar. 2019.

[25] D. Zhou, X. Li, and Y. Tang, "Multiple-vector model-predictive powercontrol of three-phase four-switch rectifiers with capacitor voltagebalancing," IEEE Transactions on Power Electronics, vol. 33, no. 7, pp. 5824-5835, July 2018.

[26] Y. Liu, W. Wu, Y. He, Z. Lin, F. Blaabjerg, and H. S. Chung, "An efficientand robust hybrid damper for LCL or LLCL-based gridtied inverter withstrong grid-side harmonic voltage effect rejection," IEEE Transactions on Industry Applications, vol. 63, no. 2, pp. 926-936, Feb. 2016.

[27] Y. Tang, W. Yao, P. C. Loh, and F. Blaabjerg, "Design of LCL filterswith LCL resonance frequencies beyond the Nyquist frequency for gridconnectedconverters," IEEE Journal of Emerging and Selected Topics in Power Electronics, vol. 4,no. 1, pp. 3-14, Mar. 2016.

[28] W. Wu, Y. Liu, Y. He, H. S. Chung, M. Liserre, and F. Blaabjerg, "Damping methods for resonances caused by LCL-fi lterbased currentcontrolledgrid-tied power inverters: An overview," IEEE Transactions on Industry Applications, vol. 64, no. 9, pp. 7402-7413, Sept. 2017.

[29] S. Jayalath and M. Hanif, "Generalized LCL-filter design algorithm forgrid-connected voltage-source inverter," IEEE Transactions on Industrial Electronics, vol.64, no. 3, pp. 1905-1915, Mar. 2017.

[30] Z. Zhang, W. Wu, Z. Shuai, X. Wang, A. Luo, H. S. H. Chung, and F.Blaabjerg, "Principle and robust impedance-based design of grid-tiedinverter with LLCL-fi lter under wide variation of gridreactance," IEEE Transactions on Power Electronics, early access, 2018.

[31] D. Chen, B. Bai, and X. Wang, "Inverter bus capacitor and parameterscalculation of DC reactor," Transactions of China Electrotechnical Society, vol. 28, no. 2, pp. 285-291, Sept. 2013.
[32] R.W. Erickson and D. Maksimovic, Fundamentals of Power Electronics, New York, USA, Springer Press, 2001.

[33] W. Wu, Y. He, and F. Blaabjerg, "An LLCL power filter for single phasegrid-tied inverter," IEEE Transactions on Power Electronics, vol. 27, no. 2, pp.782-789, Feb. 2012.

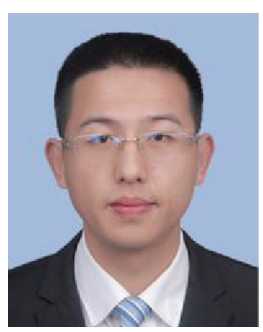

Houqing Wang was born in Jiangsu Province, China, in 1991. He received the B.S. degree in ship electrical and electronic engineering in 2015 and the M.S. degree in power electronics and power drives in 2017 both from Shanghai Maritime University, Shanghai, China, where he is currently working toward the Ph.D. degree in Power Electronics and Power Drives.

He now is a Research Assistant with the Centre for Smart Energy Conversion and Utilization Research in the City University of Hong Kong. His current research interests include digital control techniques of power converters, renewable energy generation systems, and active power filters.

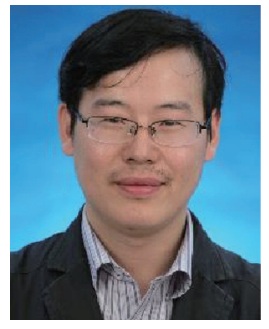

Weimin $\mathbf{W u}$ received the $\mathrm{Ph} . \mathrm{D}$. degree in electrical engineering from the College of Electrical Engineering, Zhejiang University, Hangzhou, China, in 2005.

He was a Research Engineer in the Delta Power Electronic Center (DPEC), Shanghai, China, from July 2005 to June 2006. Since July 2006, he has been a Faculty Member at Shanghai Maritime University, Shanghai, where he is currently a Full Professor in the Department of Electrical Engineering. He was a Visiting Professor at the Center for Power Electronics Systems (CPES), Virginia Polytechnic Institute and State University, Blacksburg, USA, from September 2008 to March 2009. From November 2011 to January 2014, he was also a Visiting Professor in the Department of Energy Technology, Aalborg University, Demark, working at the Center of Reliable Power Electronics (CORPE). He has coauthored over 100 papers and holds eight patents. His current research interests include power converters for renewable energy systems, power quality, smart grids, and energy storage technology.

Dr. Wu is an Associate Editor for the IEEE Transactions on Industry Electronics.

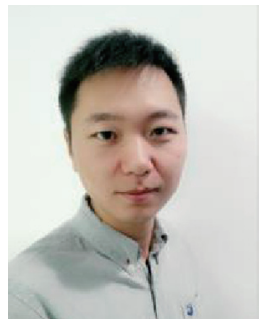

Shuai Zhang was born in Anhui Province, China, in 1992. He received the B.S. degree in ship electrical and electronic engineering in 2016 and the M.S. degree in Electrical Engineering in 2018 both from Shanghai Maritime University, Shanghai, China. Now he is working at ON Semiconductor in Shanghai as an Application Engineer.

His current research interests include power converters, renewable energy generation systems and digital control technologies for active power filters.

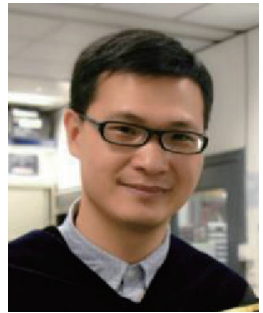

Yuanbin He received the B.Eng. and M.Eng. degrees both in electrical engineering from Shanghai Maritime University, Shanghai, China, in 2009 and 2011, respectively, and the Ph.D. degree in Electronic Engineering from the City University of Hong Kong, Kowloon, Hong Kong, in 2017.

From July 2011 to March 2013, he worked as an Associate Researcher with Nanjing FSPPowerland Technology Inc., Nanjing, China, where he has been engaged in research and development of power converters. He was a Research Assistant from April to August 2013 and a Postdoctoral Research Fellow from February to July 2017 with the City University of Hong Kong. From February to June 2016, he was a Visiting Scholar with the University of Manitoba, Winnipeg, MB, Canada. Since May 2017, he has been with Hangzhou Dianzi University, Hangzhou, China, where he is currently a Research Associate Professor in the Department of Electrical Engineering and Automation. His current research interests include control of power converters, renewable energy application, and smart grid. 


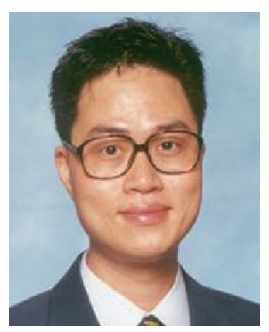

Henry Shu-Hung Chung received his B.Eng. degree in 1991 and Ph.D. degree in 1994 in Electrical Engineering, both from Hong Kong Polytechnic University.

Since 1995 he has been with the City University of Hong Kong (CityU). He is currently a Professor in the Department of Electronic Engineering, and the Director of the Centre for Smart Energy Conversion and Utilization Research. His research interests include time- and frequency-domain analysis of power electronic circuits, switched-capacitor-based converters, random-switching techniques, control methods, digital audio amplifiers, soft-switching converters, and electronic ballast design. He has edited one book, and authored eight research book chapters and over 390 technical papers including 180 refereed journal papers in his research areas, and holds 40 patents.

Dr. Chung is currently the Editor-in-Chief of the IEEE Power Electronics Letters, and Associate Editor of the IEEE Transactions on Power Electronics, and IEEE Journal of Emerging and Selected Topics in Power Electronics.

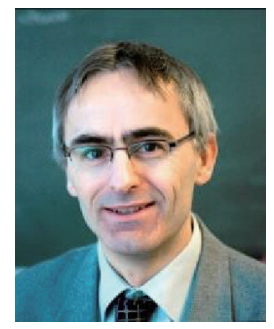

Frede Blaabjerg was with ABB-Scandia, Randers, Denmark, from 1987 to 1988. From 1988 to 1992, he was a Ph.D. student in Electrical Engineering with Aalborg University, Aalborg, Denmark. He became an Assistant Professor in 1992, an Associate Professor in 1996, and a Full Professor of Power Electronics and Drives in 1998. From 2017 he became a Villum Investigator.

His current research interests include power electronics and its applications such as in wind turbines, PV systems, reliability, harmonics and adjustable speed drives. He has published more than 450 journal papers in the fields of power electronics and its applications. He is the coauthor of two monographs and the editor of 6 books in power electronics and its applications. He was the Editor-in-Chief of the IEEE Transacions on Power Electronics from 2006 to 2012. 